\title{
Energy Efficiency : Pemanfaatan Smart Home Melalui Monitoring Daya Menggunakan Raspberry Pi
}

\author{
Akbar Hendra ${ }^{1}$, Khaidir Rahman $\mathrm{N}^{2}$ \\ Sistem Informasi STMIK AKBA ${ }^{1}$, Teknik Informatika STMIK AKBA ${ }^{2}$, \\ Email: akbarhendra@ieee.or ${ }^{1}, \underline{\text { khaidir@akba.ac.id }}{ }^{2}$
}

\begin{abstract}
ABSTRAK
Hal yang harus diperhatikan ketika membuat sebuah bangunan adalah instalasi listrik. Sebelum menentukan besar daya yang akan dipasang, penting untuk mengetahui kebutuhan listrik bangunan tersebut dengan menghitung daya yang digunakan pada masingmasing peralatan yang membutuhkan energi listrik dalam pengoperasiannya. Dengan demikian, seseorang dapat memasang daya listrik sesuai dengan kebutuhan untuk melakukan penghematan dalam mengkonsumsi daya listrik sehingga dapat menekan biaya tagihan listrik, sebab semakin tinggi daya listrik yang dipasangkan maka semakin tinggi pula biaya beban yang harus ditanggung. Dalam makalah ini kami fokus untuk meneliti mengenai kendali penggunaan listrik secara real time dari jarak jauh dengan memanfaatkan Single Board Computer(SBC).
\end{abstract}

Kata Kunci: Daya Listrik, Hemat Energi.

\section{Pendahuluan}

Penggunaan energi yang berlebihan dapat memberikan dampak yang signifikan. Disamping penggunaan energi yang kurang efektif, hal ini dapat mengakibatkan banyak dampak negatif, seperti habisnya energi dalam jangka waktu yang panjang. Oleh karena itu perlu dibuat sebuah sistemmonitoring daya listrik yang digunakan pada setiap peralatan elektronik yang dapat dilihat secara realtime menggunakan Raspberry Pi 3 Model B. Daya listrik pada sebuah lampu digunakan sebagai contoh kasus pada percobaan ini. Untuk memenuhi kebutuhan di atas, perlu dibuat sebuah sistem monitoring besaran listrik yang meliputi tegangan, arus. Untuk itu akan dibuat sistem monitoring besaran listrik yang dapat merekam data selama monitoring dilakukan dan dapat menampilkan hasil monitoring dari jarak jauh akan lebih efektif dan efisien. Kemudian untuk mengetahui besar arus digunakan sensor arus, selanjutnya daya dan faktor daya dapat diketahui melalui peralatan tersebut. Untuk pemrograman digunakan Single Board Computer atau biasa disebut dengan nama Raspberry pi, yaitu sebuah komputer mini yang harganya lebih murah dibandingkan dengan komputer PC (Personal Computer). Dengan menggunakan Raspberry pi, sensor-sensor yang digunakan dapat langsung dihubungkan ke Raspberry pi untuk dilakukan pemograman,. Raspberry pi juga dapat langsung dihubungkan ke jaringan internet layaknya komputer PC, sehingga monitoring dapat dilakukan dari jarak jauh.

\section{Kajian Pustaka}

Arus listrik adalah banyaknya muatan yang mengalir pada sebuah penghantar dalam waktu satu detik (coulombs per second) yang diukur dalam satuan ampere (A). Arus listrik dapat dirumuskan dengan persamaan berikut :

$$
I=Q t
$$


Dimana:

I =Arus listrik dalam satuan ampere (A)

$\mathrm{Q}=$ Muatan listrik dalam satuan coulomb (C)

$\mathrm{t}=$ Waktu dalam satuan detik (s)

\section{Penelitian Terkait}

Penelitian-penelitian terdahulu yang menjadi rujukan dalam penelitian ini diantaranya adalah: a. Rancang Bangun Pencatat Data kWh Meter Jarak Jauh Berbasis Mikrokontroller (Vector Anggit Pratomo, 2012). Penelitian ini menghasilkan sebuah alat untuk menghitung konsumsi energi pada rumah tangga. Alat yang dibuat terdiri dari dua bagian yaitu transmiter dan receiver. Transmiter dipasang pada $\mathrm{kWh}$ meter, sedangkan receiver digunakan untuk melihat hasil perhitungan dari jarak jauh menggunakan wireless. Untuk mendapatkan nilai konsumsi energi hanya digunakan sensor arus, dan untuk mengolah data digunakan mikrokontroller. b. Rancang Bangun Alat Ukur Arus Menggunakan Transformator Arus Berbasis Mikrokontroler ATmega32 (Dimas Adityawarman, 2014).

Penelitian ini. menghasilkan alat ukur arus dengan menggunakan current transformer sebagai sensor arus dan mikrokontroler sebagai pengolah data. Hasil pengukuran ditampilkan pada LCD.

\section{Metodologi}

4.1. Blok Diagram Sistem Untuk membuat sistem monitoring besaran listrik, alurnya adalah yang pertama dari sumber listrik masuk ke sensor arus, selanjutnya dihubungkan ke beban listrik yang digunakan. Hasil pembacaan sensor arus harus melalui ADC terlebih dahulu sebelum dikirim ke Raspberry Pi. Selanjutnya Raspberry Pi merupakan tempat membuat program untuk menyimpan hasil monitoring. Blok diagram sistem ditunjukkan pada gambar 1 .

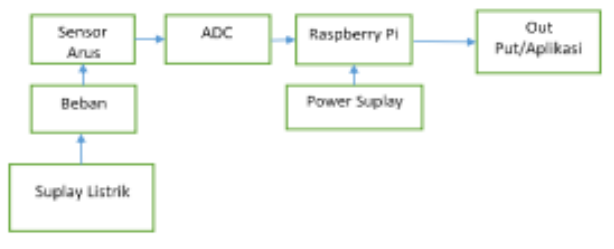

Gambar 1. Blok Diagram Sistem

4.2. Perancangan Perangkat Keras Sensor arus menggunakan ACS712 30A, sensor ini akan memberikan tegangan output yang linier dengan perubahan arus yang diukur. Sinyal keluaran ACS712 tergantung sinyal masukan, jika arus yang diukur adalah arus $\mathrm{AC}$ maka sinyal keluaran merupakan sinyal AC dan jika arus yang diukur adalah arus DC maka sinyal keluaran merupakan sinyal DC. Pada penelitian ini arus yang akan diukur adalah arus AC. Sensor yang digunakan ditunjukkan pada gambar 2.

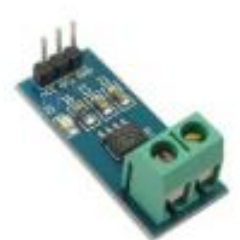

\section{Gambar 2. Rangkaian Sensor Arus}

4.3. Single Board Computer (Raspberry Pi model B) Single Board Computer (gambar 3) atau biasa disebut dengan Raspberry Pi adalah komputer berukuran kartu kredit yang dikembangkan oleh Raspberry Pi Foundation, yang memiliki fungsi yang hampir sama dengan PC kebanyakan. Model PC ini dibagi menjadi dua tipe, yaitu tipe $\mathrm{A}$ dan 
tipe B. Perbedaan keduanya hanya terletak pada memory, jumlah port USB, dan network adaptor.

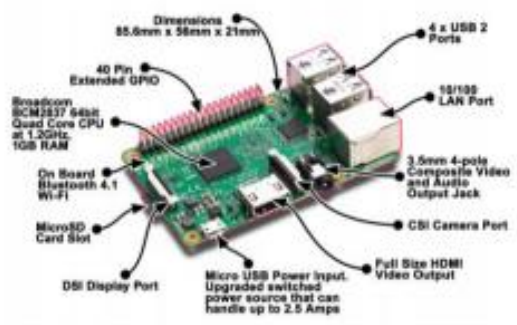

Gambar 3. Single Board Computer

Monitoring daya listrik ini dilakukan pada jaringan listrik, sensor yang dibutuhkan adalah 1 buah. Dari sensor tersebut akan didapat nilai arus I (Ampere) yang akan menghasilkan Daya beban P (Watt) dari hasil kalkulasi Arus dengan tegangan listrik PLN 1 phasa yang sudah konstan (220 VAC). Hubungan antara semua sensor dengan Raspberry Pi ditunjukkan pada gambar 4.

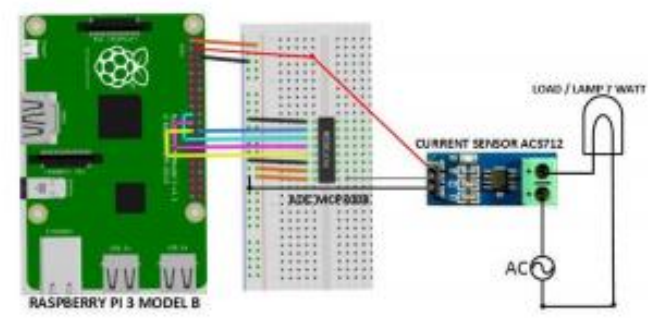

4.4. Pembuatan Program Program yang digunakan adalah Pemograman Python dengan menggunakan Raspberry Pi. Program ini meliputi:

a. Pembacaan hasil pengukuran sensor,

b. Nilai Arus didapat dari pembacaan sensor arus ACS712-20A.

c. Perhitungan untuk mendapatkan besaran Daya yang diinginkan, d. Nilai Daya merupakan hasil kali dari Arus dengan tegangan Listrik, sehingga jika nilai Arus telah diketahui maka nilai Daya dapat dihitung menggunakan persamaan

$\mathrm{P}=\mathrm{I} \times \mathrm{V}$

Dimana :

$\mathrm{P}=$ Daya $($ Watt $)$

$\mathrm{I}=$ Arus (Ampere)

$\mathrm{V}=$ Tegangan (Volt AC)

\section{HASIL DAN PEMBAHASAN}

Pengujian Sensor Arus Pengujian dilakukan dengan cara memberikan beban listrik yang nilai dayanya berubah-ubah. Kali ini yang akan diuji adalah sensor arus namun nilai tegangan juga digunakan agar nilai daya dapat dihitung melalui program yang dibuat. Hasil dari pengujian ini merupakan data arus, dan daya yang masing-masing ditampilkan pada tabel 1 .

Tabel 1 : Data Hasil Pengukuran Arus

\begin{tabular}{|l|c|c|c|}
\hline \multirow{2}{*}{ No } & \multirow{2}{*}{ Beban } & $\begin{array}{r}\text { Hasil Pengukuran Arus } \\
\text { (Ampere) }\end{array}$ \\
\cline { 3 - 4 } & & Sensor Arus & Alat Ukur \\
\hline 1 & Lampu Pijar 1 & 0,04 & 0,045 \\
\hline 2 & Lampu Pijar 2 & 0,08 & 0,089 \\
\hline
\end{tabular}

\section{Kesimpulan}

Setelah dilakukan analisa data hasil pengujian dari alat yang dibuat, dapat disimpulkan beberapa hal sebagai berikut : 1. Dapat mengetahui data hasil monitoring berupa daya listrik selama 24 jam. 2 . Konsumsi daya listrik dapat digunakan secara efektif dengan adanya sistem monitoring, yang datanya diketahui secara real-time. 3. Pada saat pengujian sensor arus tipe ACS712 diketahui bahwa sensor tersebut tidak tahan terhadap arus short circuit, dan ketika mengalami kerusakan akan memutus hubungan antara sumber listrik dan beban. 


\section{Referensi}

[1]. Kurniawan, D. Despa and $\mathrm{M}$. Komarudin, "Monitoring Besaran Listrik dari Jarak Jauh pada Jaringan Listrik 3 Fasa Berbasis Single Board Computer BCM2835," p. 9.

[2]. Adityawarman, Dimas. Rancang Bangun Alat Ukur Arus MenggunakanTransformator Arus Berbasis Mikrokontroler ATmega32. Universitas Lampung, 2014. [3] Priambodo, Hanang. Rancang Bangun Sistem Monitoring Bandwidth, Koneksi Listrik dan Temperatur Ruang Berbasis Raspberry Pi Pada Gedung Pusat Data Universitas Lampung. Universitas Lampung, 2014 